RUDY B. ANDEWEG

Leiden University

JACQUES J.A. THOMASSEN

University of Twente

\title{
Modes of Political Representation: Toward a New Typology
}

The mandate-independence controversy still features prominently in studies of political representation even though the problems with its theoretical foundation and empirical operationalization have long been recognized. This article proposes an alternative typology of modes of representation. By combining type of control (ex ante or ex post) with direction of the interactions (bottom-up or top-down), our study captures the most important aspects of the relationship between voters and representatives. We demonstrate how the typology can be used in a survey instrument by comparing the attitudes toward representation of Dutch members of Parliament with the attitudes held by voters, and by relating the views of the members to their behavior.

Studies of political representation can focus either on its outcome - the representativeness of the legislature in terms of its members' backgrounds (descriptive representation) or their opinions or votes (policy representation) — or on its nature as a relationship between voters and members of Parliament (MPs). In this paper, we seek to contribute to the understanding of political representation as a relationship. The relationship between voters and MPs has predominantly been discussed in terms of whether representatives should act as "delegates," putting instructions from the represented above their own judgment, or as Burkean "trustees," following their own judgment rather than that of their constituents. This normatively oriented "mandate-independence controversy" (Pitkin 1967) forms the basis of probably the most influential empirical typology of the style of representation: Eulau and Wahlke's delegates, trustees, and politicos (for whom "it depends" whether they follow their voters or not) (Eulau and Wahlke 1959; Wahlke et al. 1962). It is this distinction that still features prominently in many recent studies of the relationship between voters and MPs (for example, Converse and Pierce 1986; Esaiasson and 
Holmberg 1996; Judge 1999; Katz 1997; Méndez-Lago and Martínez 2002; Patzelt 1997; and Saalfeld and Müller 1997).

This persistence is remarkable, given the critique, both normative and empirical, of the typology. Back in 1967, Pitkin pointed out that the mandate-independence controversy leads us nowhere. By its very nature, representation implies that the representative cannot be identified completely with the demands or interests of the represented, and neither can the representative be completely divorced from those demands and interests: at the extreme opposites of the mandate-independence controversy we can no longer speak of representation.

So, insofar as the mandate-independence controversy contains a conceptual dispute based on the meaning of representation, both sides are right. The seemingly paradoxical meaning of representation is perpetuated in our requirements for the activity of representing: the represented must be both present and not present. The representative must really act, be independent; yet the represented must be in some sense acting through him. Hence there must be no serious persistent conflict between them. (Pitkin 1967, 154)

There is thus no answer to the mandate-independence controversy. Empirically, all representatives can be classified as politicos in Eulau and Wahlke's typology.

. . . if 0.00 means a representative's legislative record which is purely and unyieldingly Burkean, totally without regard for expressed district wishes, and 1.00 reflects a legislative record laid down at every step in response to perceived district instructions, we should be surprised if many political representatives in legislative bodies could be created much outside the limits of a narrower range, such as .30 to .70 , or even .35 to .65 . (Converse and Pierce $1986,497)$

The empirical critique of the typology also takes issue with its operationalization as a relationship between an individual MP and a geographical constituency, without reference to the existence of disciplined political parties (Thomassen 1994). In their analysis of the style of political representation in France (in comparison with the United States and the Netherlands), Converse and Pierce transformed the dimension from trustee to delegate into a triangle by adding the loyal partisan as a third role type (Converse and Pierce 1986, 664-96). As they argue themselves, however, the loyal partisan is not an independent third role, but merely another variety of the delegate, with the party rather than the people as the focus of representation. Converse and Pierce's triangle is important for our understanding of the legislator's behavior, but it does not help us understand political representation as a relationship between the representative (individual or collective, meaning, the party) and the voters. 
TABLE 1

Style of Representation (with party voters as focus), 1972-2001

\begin{tabular}{lcccc}
\hline & 1972 & 1979 & 1990 & 2001 \\
\hline Delegates ("Follow party voters") & 7 & 7 & 10 & 21 \\
Politicos ("It depends") & 22 & 29 & 34 & 40 \\
Trustees ("Follow own judgment") & 71 & 64 & 56 & 40 \\
& 100 & 100 & 100 & 101 \\
N & 141 & 129 & 130 & 129 \\
\hline
\end{tabular}

Source: Dutch Parliamentary Studies.

The critique of the Eulau-Wahlke typology and of the mandateindependence controversy on which it is based is borne out in our own interviews with Dutch MPs, held at regular intervals over the past three decades. ${ }^{1}$ Given the absence of electoral districts in the current Dutch electoral system, members were asked whether MPs should vote in Parliament according to the views of their party's voters or according to their own views. MPs who advocate adherence to the party voters' views can be regarded as delegates, those who argue that MPs should stick to their own judgment are trustees, and those for whom the answer depends on the issue belong to the category of politicos.

It would seem that, at least since 1972, the Burkean trustee has gradually been losing ground, but primarily to the politico, who cannot choose between the two main alternatives and answers that "it depends" whether representatives should follow their party's voters or their own opinions. As can be seen in Table 1, by 2001, no fewer than $40 \%$ of MPs belonged to that indeterminate category. Even MPs who eventually did pick one of the alternatives complained to their interviewers: "That question is wrong," "It does not work that way," "That is almost unanswerable," "You cannot deal with this in a black-and-white fashion," "That is a silly question," "Neither answer is correct," "The answering categories are incomplete," and so on. In other words, we can apply the Eulau-Wahlke typology in the sense that MPs will give answers to our questions, but the distinction does not seem to provide meaningful insights into the relationship between the represented and the representatives. 


\section{Toward a New Typology}

The search for a new approach to the variety of interactions that make up political representation seems long overdue. Here, we present a new typology that avoids at least some of the ambiguities resulting from the use of the trustee-delegate categories. We demonstrate how this new typology can be used in a survey instrument to obtain empirical findings, and we show that the typology proves useful for comparing the views of MPs regarding political representation with the views of voters and with the MPs' own behavior.

Fortunately, this typology can build on some recently developed perspectives on political representation, including the application of the microeconomic principal-agent framework to politics (Bendor, Glazer, and Hammond 2001). In this framework, political representation is viewed as a delegation of power from a constituency or group of voters (the principal) to a particular party or MP (the agent), and the central question is how, and to what extent, the principal can prevent the agent from acting in a way contrary to the demands or interests of the principal. Instruments to prevent such agency loss can either precede the representative relationship (ex ante controls, such as the screening of potential candidates or parties, or drawing up a contract) or follow it (ex post controls, such as monitoring and reporting requirements, or institutional checks). Ex ante controls have as the ultimate sanction the decision by the principal not to engage the agent; ex post controls have as the ultimate sanction the decision by the principal to discontinue the relationship with the agent. Mansbridge has introduced the terms promissory representation, for representative relations largely based on ex ante controls, and anticipatory representation, for such relations that rely primarily on ex post controls (2003). Representative relations will usually rely on a mixture of ex ante and ex post controls, but the emphasis varies. In general, ex ante controls seem to be more characteristic of parliamentary democracies than of presidential democracies, with consequences for the efficiency and transparency of the political system (Strøm 2000, 2003).

Applying agency theory to political representation has one important drawback: it is unidirectional in the sense that it assumes the voters have both clear policy preferences that are to be translated into policy by the representatives, and control mechanisms at their disposal to restrict the representatives' room for maneuver. Representatives are merely recipients of the voters' demands, and objects of their control. Other (less Rousseauist, more Madisonian or Schumpeterian) views of political representation are not unidirectional and see representative 
democracy as a wedding of leadership and popular control (Brennan and Hamlin 1999). Although representative democracy is often described as classical direct democracy that had to be watered down by adding representation to overcome problems of scale, the historical reality is a more-elitist one of feudal forms of representation and leadership to which elements of popular control were added later (Manin 1997). Esaiasson and Holmberg include both the bottom-up and top-down directions in their study of representative democracy in Sweden (Esaiasson and Holmberg 1996). In representation run from below, the process starts with the citizens, who enter the political process with crystallized views. Political representation then serves to translate these views as best as possible into government policy, as it is described in the principal-agent model. In representation run from above, the representatives are assigned a more-active role. The process of political representation starts with the representatives, who enter the political process with their views and put these views to the citizens for their approval. In representation from below, popular preferences are exogenous, and representative democracy can be described as populist; in representation from above, popular preferences may well be endogenous to the interactions with politicians, and representative democracy can therefore be characterized as elitist.

According to Esaiasson and Holmberg, the touchstone for representation from below is responsiveness, the degree to which representatives express the opinions of the represented. The touchstone for representation from above is accountability. But in Esaiasson and Holmberg's description of their showcase model of representation from above (the responsible party model), the authors are more ambivalent: "Parties compete for voters' support on the basis of programs summarizing the policies they intend to pursue during the coming mandate period. ... At the next election, finally, the voters get the opportunity to hold the governing party or coalition accountable for what it has and has not done, and they take position on the programs of the parties for the subsequent mandate period" (Esaiasson and Holmberg 1996, 3). The concept of a mandate later becomes the defining element (310-13). A mandate authorizes the parties to pursue particular policies in the years to come, whereas accountability forces the parties to seek approval for policies pursued in the years past. Authorization is possible without accountability and vice versa (Manin, Przeworski, and Stokes 1999). By combining the two, Esaiasson and Holmberg assume that people vote prospectively (mandate, or ex ante controls) and retrospectively (accountability, or ex post controls) at the same time. This is only possible if voters view both future plans and past performance either positively 
FIGURE 1

Modes of Political Representation

\begin{tabular}{|c|c|c|c|}
\hline \multicolumn{2}{|c|}{ Control Mechanism } \\
\hline \multirow{7}{*}{ Direction } & \multirow{2}{*}{ Ex Ante } & \multicolumn{2}{c|}{ Ex Post } \\
\cline { 3 - 4 } & \multirow{2}{*}{ From Above } & authorization & accountability \\
\cline { 3 - 4 } & & & \\
& From Below & delegation & responsiveness \\
& & & \\
\end{tabular}

or negatively, but if the two evaluations diverge, voters can make a choice only by assigning different weights to mandate and accountability (or they remain so cross-pressured that they abstain from voting).

Fortunately, Esaiasson and Holmberg's distinction solves a problem for agency theory (the problem of unidirectionality), and agency theory solves a problem for Esaiasson and Holmberg (the problem of not distinguishing ex ante and ex post controls). By combining direction (from above or from below) and type of control (ex ante or ex post), we achieve a typology of four modes of political representation. The modes are presented in Figure 1.

\section{Delegation}

Representation from below and ex ante is probably the ideal-type of representative democracy as delegation, but it makes demanding assumptions: The voters must have preferences that are both exogenous and stable, and the political agenda must be predictable.

\section{Responsiveness}

Representation from below and ex post is best illustrated by analyses of political representation in the United States, with its extreme emphasis on responsiveness: Stimson, MacKuen, and Erikson (1995) 
call it "dynamic representation" and King (1997, 165-66) calls it "hyperresponsiveness." The driving force is the representative's desire to please (Mansbridge 2003) or fear: "Like antelope in an open field, [politicians] cock their ears and focus their full attention on the slightest sign of danger" (Stimson, MacKuen, and Erikson 1995, 559). This mode also has been called "running scared" (the title of King 1997). This form of representation assumes that voters have exogenous preferences, but neither these preferences nor the political agenda need to be stable. Representatives are assumed to be able to gauge changing popular preferences, and the threat of removal from office can only be credible if there is electoral choice, that is, an opposition, and if representatives are willing and allowed to seek reelection. (If the representative is a party, rather than an individual, then this assumption poses no problem.)

\section{Authorization}

An example of representation from above and ex ante is the responsible party model (American Political Science Association 1950; Ranney 1954), in which cohesive political parties present distinct programs to the voters, who then form preferences for one program or another and vote accordingly. Through these votes, the party is mandated to (try to) implement its manifesto; the central role of the party program in this mode reflects "an intense commitment to a mandate theory of representation" (Converse and Pierce 1986, 706). Voters are not required to have exogenous preferences, but if they lack such preferences, they are assumed to be able to develop them in reaction to the campaign (endogenous preferences). It is therefore also assumed that there is electoral choice: Voters are able to distinguish between two or more representatives or parties. A further assumption is that the political agenda is predictable.

\section{Accountability}

Representation from above and ex post is not often recognized in the literature, but in this mode the representative (party or politician), like a political entrepreneur, "is essentially proactive, identifying and promoting policies that she believes will be appreciated ex post rather than preferred ex ante" (Brennan and Hamlin 1999, 115). This mode of representation makes the fewest assumptions. Voter preferences may be exogenous or endogenous, stable or changing, and the agenda need not be predictable. The only assumptions are the availability of an 
alternative, that is, electoral choice, and the member's ambition and opportunity to stand for reelection (again, where representatives are parties, this motivation is not a question). Another usual assumption for this mode is that the voters are able to clearly assign responsibility for government performance (Manin, Przeworski, and Stokes 1999, 47). Separation of powers and semipresidentialism obfuscate responsibility, as does coalition government, whereas single-party government within a parliamentary system supposedly optimizes accountability. But this logic confuses two stages in the chain of delegation and accountability in a parliamentary system; voters delegate to Parliament, and Parliament delegates to the government. Voters can reward and punish parties both for their performance in government and their performance in Parliament. Divided government and coalition government may increase the costs of information for voters, but they do not render representation from above and ex post impossible.

Depending on the political system, the voters in these four modes of representation can be operationalized as constituency voters or a national electorate, and the representatives can be individual MPs or political parties. The modes of representation should be regarded as ideal-types (in the Weberian sense) and used to compare democratic political systems: a particular system's design may contain elements (binding mandates, recall elections, electoral systems that facilitate accountability over mandate or vice versa, and so forth) that approximate one mode of representation more than other modes. The typology can also be used at the individual level to study the attitudes of both MPs and voters toward the representative relationship. In the remainder of this paper, we aim to demonstrate the typology's value for the study of such individual attitudes.

\section{Dutch Voters and MPs, and the Modes of Representation}

In order to gauge the attitudes of voters and MPs toward the dimensions and modes of political representation, we operationalized the two dimensions of the typology in the form of two questions. The first question:

In their relationship with their voters, politicians may emphasize different aspects. Which of these two aspects do you think is most important?

- translating the political views of citizens into policy as accurately as possible;

— seeking support from the voters for the political views of their own party. 
TABLE 2

The Two Dimensions of Representation: MPs and Voters (in percentages)

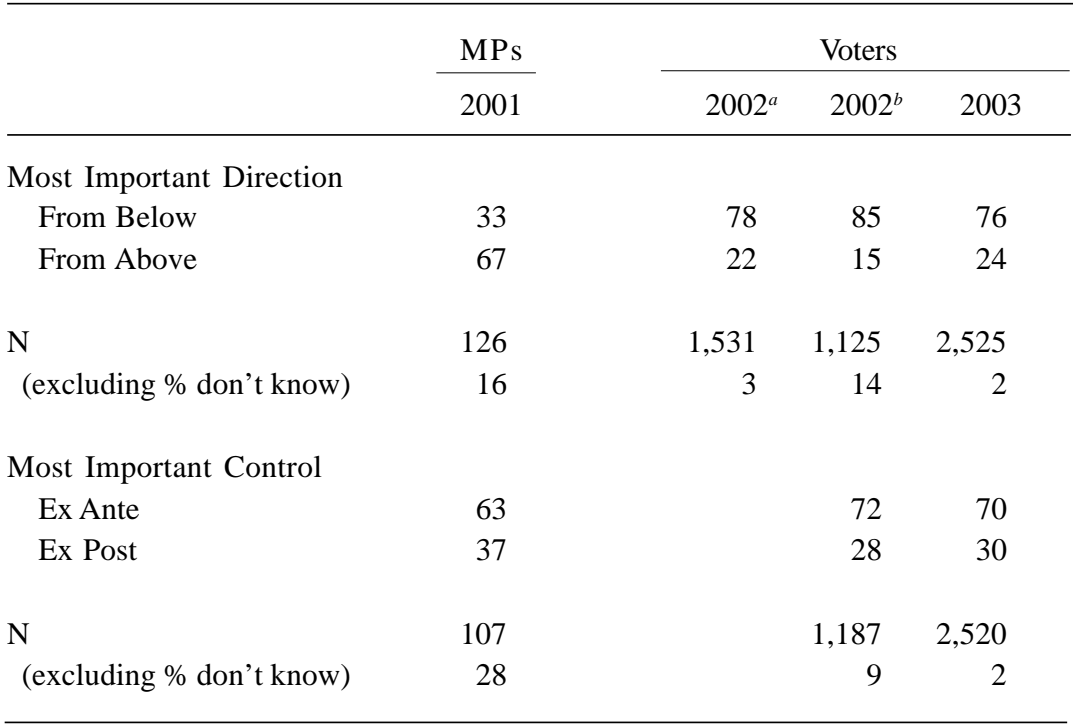

Sources: For MPs, Dutch Parliamentary Study 2001. For the voters, 2002 ${ }^{a}$ : Dutch National Election Study, May 2002; 2002 ${ }^{b}$ : NIPO telepanel survey, October 2002; 2003: Dutch National Election Study.

differentiates between representation from below and representation from above. The second question:

In our political system, elections have various functions. Which of these two functions do you think is most important?

- in elections, politicians account to the voters for their actions in the past;

- in elections, politicians put their plans for the future to the voters.

differentiates between ex post controls (retrospective voting) and ex ante controls (prospective voting). Table 2 charts responses from voters and MPs.

The reactions of MPs to these questions (which were taperecorded) indicate that the original Dutch versions of these two questions primarily elicited normative replies. Only small numbers of voters and MPs were unable to answer the questions. The only exception occurred when the second question was put to MPs in the 2001 Parliamentary 
Study: $28 \%$ failed to choose between the two alternatives, arguing that it was impossible to separate the two: "Both are equally important," "No voter is voting for you if your past performance has not given them the confidence that you will fulfill your promises, and if you do not have good plans, they will not vote for you either," "If you do only one of the two, you are doing only half the work," and so on. Although they maintained that it was impossible to choose, some respondents argued that the emphasis could be on one or the other depending on whether one sought election or reelection: "Both are important because one applies to new parties and the other to parties who want to be elected again." Our typology is indeed asymmetrical; from the perspective of the representatives, the two modes relying on ex post controls assume incumbency, whereas the two modes that employ ex ante controls do not.

From the perspective of the voters, however, this asymmetry is not a problem. They can use their vote as an ex post control to punish incumbents by voting for a new challenger. According to a 2002 NIPO Telepanel survey, $43 \%$ of the voters for the new populist List Pim Fortuyn (LPF) saw elections primarily as an ex post mechanism, as compared to $25 \%$ of the voters who voted for parties already represented in Parliament. Incumbent MPs may campaign on both their records and their promises, but voters cannot attach equal weight to both functions of elections. As previously mentioned, it is possible for voters to evaluate both performance and plans positively, or to react negatively to both. As ex ante and ex post controls then lead to congruent decisions, it becomes impossible to distinguish the two functions. On the other hand, if voters like a party's record but dislike its manifesto, or vice versa, one of the two electoral functions must be given preference; it is impossible to vote retrospectively and prospectively at the same time. Additional institutional features may emphasize one electoral function or the other: Legally binding mandates for representatives reinforce elections as ex ante controls (but they were abolished long ago in the Netherlands and in most other Western democracies), and the possibility of recall reinforces the ex post control function of elections (but such provisions have nowhere been introduced at the national level). Currently, almost everywhere, elections constitute one instrument for two functions, and it is impossible to optimize both functions at the same time (Manin, Przeworski, and Stokes 1999).

It may be possible to rephrase the question that we put to MPs in such a way as to force them to make a choice between ex ante and ex post controls, but it is interesting that the voters have fewer problems in choosing between the two functions of elections. In the 2002 NIPO electronic survey, more than $90 \%$ made a choice despite the fact that 
TABLE 3

The Relationship between Direction and Control Mechanism in Political Representation

\begin{tabular}{lccccc}
\hline & Chi square & $\mathrm{df}$ & $\mathrm{p}$ & $\mathrm{N}$ & Cramer's V \\
\hline MPs (2001) & 1.484 & 1 & .223 & 104 & .119 \\
Voters (2002) & 2.456 & 1 & .117 & 1,103 & .047 \\
Voters (2003) & 16.37 & 1 & $<.000$ & 2,483 & .081 \\
\hline
\end{tabular}

Sources: For MPs, Dutch Parliamentary Study 2001. For voters, 2002: NIPO telepanel survey; 2003: Dutch National Election Study.

in this study the respondents were explicitly presented with the alternative "Don't know." When that option was not made explicit, only $2 \%$ of voters failed to make a choice in the 2003 National Election Study.

Apart from the inability of some MPs to choose between the ex ante and ex post control functions of elections, the typology seems to survive its first application rather well. The question about the direction of representation was put to the voters in three different studies within a year (Spring 2002-Winter 2003), with very similar results. Two of these studies also asked the question about the type of control mechanism, and the results were virtually identical (see Table 2). If we were measuring non-attitudes, then we would not expect such stable outcomes, but we cannot completely exclude that possibility on the basis of aggregate outcomes. Fortunately, the 2003 National Election Study includes a panel of respondents who had been interviewed in the 2002 National Election Study as well. This feature allows us to assess attitude stability at the individual level for the voters on at least one of the two questions (the question about the direction of representation). Of the 1,297 respondents in the panel, 1,250 (96\%) answered the question in both waves, and $75 \%$ of those chose the same alternative on both occasions.

The two questions are intended to tap different dimensions of political representation, and, consequently, the answers to the two questions should not be strongly correlated. One might think that there is overlap between alternatives on the two dimensions (seeking support from the voters for the political views of the party, and putting plans for the future to the voters), but such fears are unfounded, as can be seen from the data in Table 3.

Only for the voters in the 2003 National Election Study did we find a statistically significant association between the two questions. 
This result is not surprising when we consider chi-square's sensitivity to sample size and the large number of respondents $(\mathrm{N}=2,483)$. The association is still quite weak (Cramer's $\mathrm{V}=.081$ ). In this National Election Study, the two questions were put together, and in the 2002 NIPO internet panel study, the respondents even had both questions on their screen, further increasing the risk of "contamination." Yet, the association between the two questions was weak and statistically insignificant in this study, despite the fairly large number of observations $(\mathrm{N}=1,103)$.

Finally, the new typology should also be different from the EulauWahlke typology of the style of representation. Ignoring for the moment the criticisms of this concept and its operationalization, we crosstabulated the MPs' answers to the question of whether MPs should follow their voters' or their own judgment with their answers to the questions about the direction and the type of control mechanism, both separately and in combination as our four-fold typology of modes of representation. There is hardly any difference between delegates and trustees with regard to the importance that they attach to ex ante or ex post controls (Cramer's V $=.138, p=.379$ ). ${ }^{2}$ Trustees are slightly more inclined than delegates to see representation from above as most important, but the association is not statistically significant (Cramer's $\mathrm{V}=.146, p=.277$ ). Finally, there is no significant association between style and the four modes (Cramer's $\mathrm{V}=.317, p=.126$ ).

\section{Varying Modes of Representation}

From Table 2 it is clear that not all MPs and not all voters have the same attitudes toward the dimensions and modes of representation. The importance of political parties in Dutch politics makes it plausible that some of the variation in attitudes among MPs can be accounted for by party. MPs from governing parties may, for example, emphasize that the government has received a mandate for its policies in the previous elections (representation from above and ex ante), whereas MPs from opposition parties may argue that they are more in touch with current voter demands and that the elections should serve to throw the incumbent "rascals" out (representation from below and ex post). Another hypothesis is that MPs from parties with highly ideological profiles tend to assign more importance to representation from above than do parties of a catch-all nature: Ideologues do not need the voters to tell them what should be done; they merely need the voters' consent for their own plans. In addition to party, an MP's experience is likely to affect that member's attitudes toward representation. For example, a 
TABLE 4

Determinants of MPs' Attitudes toward Political Representation

\begin{tabular}{|c|c|c|c|c|c|c|c|c|}
\hline \multirow[b]{3}{*}{ Party } & \multicolumn{2}{|c|}{ Direction } & \multicolumn{2}{|c|}{ Control } & \multicolumn{4}{|c|}{ Modes } \\
\hline & \multirow{2}{*}{$\begin{array}{c}\text { From } \\
\text { Below }\end{array}$} & \multirow{2}{*}{$\begin{array}{l}\text { From } \\
\text { Above }\end{array}$} & \multirow[b]{2}{*}{ Ex Ante } & \multirow[b]{2}{*}{ Ex Post } & \multicolumn{2}{|c|}{ From Below } & \multicolumn{2}{|c|}{ From Above } \\
\hline & & & & & Ex Ante & Ex Post & Ex Ante & Ex Post \\
\hline Government & 35.8 & 64.2 & 64.1 & 35.9 & 23.8 & 14.3 & 41.3 & 20.6 \\
\hline Opposition & 28.9 & 71.1 & 60.5 & 39.5 & 12.2 & 17.1 & 48.8 & 22.0 \\
\hline Cramer's V & \multicolumn{2}{|c|}{$.07(p=.43)$} & \multicolumn{2}{|c|}{$.036(p=.706)$} & \multicolumn{4}{|c|}{$.146(p=.531)$} \\
\hline More Ideological & 4.8 & 95.2 & 68.2 & 31.8 & - & 5.0 & 70.0 & 25.0 \\
\hline Less Ideological & 39.0 & 61.0 & 61.2 & 38.8 & 23.8 & 17.9 & 38.1 & 20.2 \\
\hline Cramer's V & $.271(p$ & $=.002)$ & $.059(p$ & $=.545)$ & & .316 & $=.016)$ & \\
\hline \multicolumn{9}{|l|}{ MP's Incumbency } \\
\hline$<4$ years & 34.3 & 65.7 & 49.1 & 50.9 & 18.2 & 20.0 & 30.9 & 30.9 \\
\hline $4-8$ years & 44.4 & 55.6 & 67.9 & 32.1 & 28.6 & 14.3 & 39.3 & 17.9 \\
\hline$>8$ years & 13.0 & 87.0 & 90.9 & 9.1 & 9.5 & 4.8 & 85.7 & 0.0 \\
\hline Cramer's V & \multicolumn{2}{|c|}{$.223(p=.043)$} & \multicolumn{2}{|c|}{$.339(p=.002)$} & \multicolumn{4}{|c|}{$.327(p=.001)$} \\
\hline
\end{tabular}

Note: Entries are row percentages. Government = PvdA, VVD, D66; Opposition = CDA, SP, Green Left, Christian Union, SGP. More ideological = SP, Green Left, Christian Union, SGP; Less ideological = PvdA, CDA, VVD, D66.

Source: Dutch Parliamentary Study 2001

seasoned MP is more likely to feel that the best division of labor is for politicians to elaborate policy proposals and for voters to react to those proposals (representation from above and ex ante).

The hypothesis that membership of a governing party would lead to a different attitude toward representation than would opposition status is roundly rejected by the data, as is shown in Table 4 . The associations are weak and insignificant, and, with respect to representation from below/from above, the data point in the opposite direction. Apparently, the attitudes toward political representation are not determined by a temporary institutional position. There is more support for the other two hypotheses. MPs from the ideologically more-pronounced parties of the Left (the Socialist Party and the Green Left) and the Right (the two orthodox Protestant parties) assign significantly more importance to representation from above than do MPs from the more-centrist parties. A closer look shows that Labor Party (PvdA) MPs have rather similar attitudes as MPs from smaller ideological parties, despite the fact that the Labor Party (in government for a third consecutive term 
at the time of our study) is widely perceived as having moved to the center. Its then-leader, Wim Kok, was well known for his insistence that the party should "shed its ideological feathers." Perhaps the Labor MPs' "from above" attitudes reflect their party's more-ideological tradition. Length of incumbency also has the hypothesized effect, although the importance given to representation from above does not increase monotonously.

There is less of a partisan pattern to the voters' attitudes. One of the few exceptions has already been mentioned: In 2002, LPF voters attached more weight to the ex post function of elections. This party's voters were somewhat more inclined to see representation from below as most important. In the 2002 and 2003 National Election Studies, $85 \%$ to $86 \%$ of LPF voters opted for representation from below, as compared to $76 \%$ to $78 \%$ of the electorate as a whole. More generally, we expect voters' level of education to be associated with the importance that they assign to representation from below because "cognitive mobilization" has been linked to a shift from "elite-directed" to "elitedirecting" participation (see, for example, Inglehart 1977). As the data in Table 5 show, voters with more than elementary education do indeed emphasize representation from below more than voters with only elementary education, but the association is not strong.

The most striking difference in the attitudes toward political representation is not between various categories of MPs or of voters, but rather between MPs and voters. As Table 2 clearly shows, MPs are more inclined than voters to emphasize elections as an ex post mechanism of popular control, but the difference is not very pronounced, and a large majority of both MPs (63\%) and voters (70-72\%) see the prospective function of elections as more important than the retrospective function. This finding supports Fearon's suggestion that

[V]oters think about elections more as opportunities to try to select good types than as sanctions to deter shirking by future incumbents. . . The popular dislike of office seeking, support for term limits, the premium put on politicians being principled and consistent, and the absence of concern about "last-period effects" all suggest that voters think about elections primarily in terms of selection. (Fearon 1999, 82)

To a large extent, MPs seem to share the voters' view of this aspect of political representation.

In contrast, the difference between voters and MPs when it comes to representation from above or from below is huge. The relevant question has been posed to voters in three national surveys, and all three show that more than three-quarters of the voters see representation from below as the more-important mode. For MPs, it is the other way 
TABLE 5

Cognitive Mobilization and Voter Attitudes

toward Political Representation

\begin{tabular}{|c|c|c|c|c|c|c|c|c|}
\hline \multirow{3}{*}{$\begin{array}{l}\text { Level of } \\
\text { Education }\end{array}$} & \multicolumn{2}{|c|}{ Direction } & \multicolumn{2}{|c|}{ Control } & \multicolumn{4}{|c|}{ Modes } \\
\hline & \multirow{2}{*}{$\begin{array}{l}\text { From } \\
\text { Below }\end{array}$} & \multirow{2}{*}{$\begin{array}{l}\text { From } \\
\text { Above }\end{array}$} & \multirow[b]{2}{*}{ Ex Ante } & \multirow[b]{2}{*}{ Ex Post } & \multicolumn{2}{|c|}{ From Below } & \multicolumn{2}{|c|}{ From Above } \\
\hline & & & & & $\overline{\text { Ex Ante }}$ & Ex Post & Ex Ante & Ex Post \\
\hline Elementary & 69.7 & 30.3 & 67.4 & 32.6 & 45.4 & 25.1 & 22.0 & 7.5 \\
\hline Secondary & 81.9 & 18.1 & 70.0 & 30.0 & 55.7 & 26.2 & 14.1 & 4.0 \\
\hline Higher & 72.4 & 27.6 & 72.1 & 27.9 & 50.8 & 21.6 & 21.3 & 6.2 \\
\hline \multirow[t]{2}{*}{ Cramer's V } & \multicolumn{2}{|c|}{$.125(p=.000)$} & \multicolumn{2}{|c|}{$.035(p=.214)$} & \multicolumn{4}{|c|}{$.127(p=.000)$} \\
\hline & \multicolumn{2}{|c|}{$\mathrm{N}=2,511$} & \multicolumn{2}{|c|}{$\mathrm{N}=2,506$} & \multicolumn{4}{|c|}{$\mathrm{N}=2,477$} \\
\hline
\end{tabular}

Source: Dutch National Election Study 2003.

around: Two-thirds of the representatives choose representation from above as the more-important mode. In their study of political representation in France, Converse and Pierce reported that most deputies see their role as delegates of their party, whereas most voters feel that deputies should act as delegates of their constituency's voters (Converse and Pierce 1986, 687-90). Those authors do not offer an explanation for this pattern. In light of our findings for the Netherlands, the factor underlying the difference between voters and MPs may not be the focus of representation (with politicians preferring the party, and voters preferring the constituency), but rather the direction of representation (with politicians preferring representation from above, and voters opting for representation from below).

The result is that the distribution of voters over the four modes of representation clearly diverges from the distribution of MPs across the same typology. It is clear from Table 6 that the representatives have very different attitudes with respect to political representation from those they represent: Most voters see representation from below/ex ante as most important, with from below/ex post taking second place and from above/ex post rarely mentioned, but a plurality of MPs opt for from above/ex ante with from above/ex post coming in second.

Perhaps it is not surprising that elites have an elitist view of representation and that the people have a populist view of representation. In politics, as in social life in general, however, it bodes ill for any relationship if the two partners have such divergent expectations of 
TABLE 6

The Modes of Representation and Votes Compared

(in percentages)

\begin{tabular}{|c|c|c|c|c|}
\hline & & Control & chanism & \\
\hline \multirow{3}{*}{ Direction } & \multirow[b]{2}{*}{ From Above } & Ex Ante & \multicolumn{2}{|l|}{ Ex Post } \\
\hline & & $\begin{array}{ll}\text { MPs 2001: } & 44 \\
\text { Voters 2002: } & 12 \\
\text { Voters 2003: } & 18\end{array}$ & $\begin{array}{l}\text { MPs 2001: } \\
\text { Voters 2002: } \\
\text { Voters 2003: }\end{array}$ & $\begin{array}{r}21 \\
4 \\
5\end{array}$ \\
\hline & From Below & $\begin{array}{ll}\text { MPs 2001: } & 19 \\
\text { Voters 2002: } & 60 \\
\text { Voters 2003: } & 52\end{array}$ & $\begin{array}{l}\text { MPs 2001: } \\
\text { Voters 2002: } \\
\text { Voters 2003: }\end{array}$ & $\begin{array}{l}15 \\
25 \\
25\end{array}$ \\
\hline \multicolumn{5}{|c|}{$\begin{array}{l}\text { MPs } 2001 \mathrm{~N}=104 \\
\text { Voters } 2002 \mathrm{~N}=1,103 \\
\text { Voters } 2003 \mathrm{~N}=2,491\end{array}$} \\
\hline
\end{tabular}

Note: Percentages are of the total number of MPs and voters, respectively.

Sources: For MPs, Dutch Parliamentary Study 2001. For voters, 2002: NIPO telepanel survey; 2003: Dutch National Election Study.

that relationship. In many democracies, a "confidence gap" between voters and politicians is said to be widening (see, for instance, Pharr and Putnam 2000), and it does not seem implausible to suggest that the gap in attitudes toward representation illustrated in Table 6 may contribute to this confidence gap. This logic assumes that voters can be aware that their representatives hold different attitudes toward their relationship. Some of the survey questions customarily used to measure voters' external political efficacy may actually show the extent of this awareness. For example, according to the 2003 Dutch National Election Study, $45 \%$ of voters agreed that "Parties are only interested in my vote, not in my opinion." If we may generalize from such findings, then we should expect that those voters whose views of political representation are most different from those of the MPs (that is, those voters who attach most importance to representation from below and, to a lesser extent, to representation ex post) will be most dissatisfied with the functioning of Dutch democracy. 
TABLE 7

Voter Attitudes toward Political Representation and Satisfaction with the Functioning of Democracy

\begin{tabular}{lc}
\hline & Percentage Very/Fairly Satisfied \\
\hline Most Important Direction & 82 \\
$\quad$ From Below & 84 \\
From Above & $.032(p=.252)$ \\
Cramer's V & 1,265 \\
$\mathrm{~N}$ & \\
& \\
Most Important Control & 83 \\
$\quad$ Ex Ante & 81 \\
$\quad$ Ex Post & $.022(p=.436)$ \\
Cramer's V & 1,257 \\
N & \\
& \\
Mode of Representation & 83 \\
From Below/Ex Ante & 79 \\
From Below/Ex Post & 84 \\
From Above/Ex Ante & 88 \\
From Above/Ex Post & \\
Cramer's V & 1,247 \\
N &
\end{tabular}

Source: Dutch National Election Study 2003.

As Table 7 illustrates, the associations between the dimensions and modes of representation on the one hand and satisfaction with democracy on the other hand are in the predicted direction: Satisfaction with democracy is lower among voters who view representation from below and representation ex post as most important. The associations are weak, however, and not significant. Compared to most other countries, the Netherlands still has relatively high satisfaction with democracy; it would probably be easier to find an association between the divergent views on representation on the one hand and satisfaction with the functioning of democracy on the other hand in countries with greater variation in the dependent variable. The consequences of the incongruence between elite and mass attitudes toward political representation for the legitimacy of representative democracy clearly warrant further research. 


\section{Behavioral Consequences}

Finally, in order to establish the usefulness of the new typology of political representation, we should compare the normative views of MPs with their behavior and, in particular, with their interactions with the people they represent. The Dutch Parliamentary Study asked MPs how many hours they work per week (on average 65 hours), and how many of those hours they spend on various activities. With regard to representation, the time spent on party activities (other than those within the parliamentary party), on contacts with individual citizens, and on contacts with social organizations are of particular relevance.

Both the views regarding direction of representation and type of control mechanism are related to the time that MPs invest in various activities. Table 8 shows that MPs who see representation from above as most important spend more time on party activities, and MPs who view representation from below as most important invest more time in contacts with individual citizens and social organizations. Similarly, MPs who emphasize the retrospective function of elections (ex post controls) spend more time with citizens and social organizations than within their parties, whereas the opposite holds true for MPs who see elections as occasions to present plans for the future (ex ante controls). The result is that MPs who see representation as from below/ex post devote almost twice as much time to contacts with citizens and organizations than do MPs who see representation from above/ex ante as most important.

\section{Discussion}

The literature has long recognized the limitations of the theoretical foundation and the empirical operationalization of the Eulau-Wahlke typology of representational style that continues to dominate the study of that aspect of political representation. Ours is a first attempt at designing a typology that captures the most important aspects of the interactions between voters and MPs, and that can travel across different political and party systems. This typology builds on existing literature by combining the focus on the type of control mechanism from principal-agent theory with the emphasis on the direction of the interactions introduced by Esaiasson and Holmberg. The typology has been operationalized for studying the attitudes toward representation of both voters and MPs in the Netherlands, and the results show that the answers to our questions reflect real and relatively stable attitudes and that the two dimensions in the typology are independent from each 
TABLE 8

The Modes of Representation and Time Spent on Representational Activities

\begin{tabular}{lccc}
\hline & \multicolumn{3}{c}{ Hours per Week Spent by MPs on } \\
\cline { 2 - 4 } & $\begin{array}{c}\text { Activities within } \\
\text { Own Party }\end{array}$ & $\begin{array}{c}\text { Contacts with } \\
\text { Individual Citizens }\end{array}$ & $\begin{array}{c}\text { Contacts with } \\
\text { Social Organizations }\end{array}$ \\
\hline Most Important Direction & & & \\
$\quad$ From Below & 5.9 & 7.7 & 8.4 \\
From Above & 7.6 & 5.4 & 6.7 \\
F & 1.831 & 7.19 & 3.22 \\
Most Important Control & & & \\
Ex Ante & 7.5 & 5.4 & 6.2 \\
Ex Post & 6.8 & 6.7 & 9.5 \\
F & .261 & 1.917 & 11.728 \\
Mode of Representation & & & 10.2 \\
From Below/Ex Post & 5.8 & 9.1 & 7.4 \\
From Below/Ex Ante & 6.0 & 6.5 & 8.7 \\
From Above/Ex Post & 7.4 & 5.4 & 5.7 \\
From Above/Ex Ante & 8.0 & 5.0 & 4.288 \\
F & .566 & 3.244 & \\
\hline
\end{tabular}

Source: Dutch Parliamentary Study 2001.

other and unrelated to the Eulau-Wahlke typology. The new typology helps bring to light significant divergences between the views that representatives have of political representation and the views of the people they represent, and the typology appears to be correlated to the actual behavior of MPs.

Although these results are encouraging, there is much room for improvement, in particular with regard to the operationalization of the two dimensions. We discussed the failure of more than a quarter of the MPs in our study to choose between the prospective and retrospective functions of elections. Moreover, the questions were attempts to ascertain what respondents view as important, not what they perceive the current practice of representation to be. In order to further analyze the potential impact of the incongruence in MP and voter attitudes toward representation, future studies should inquire both into what respondents see as the empirical reality of representation and what they think is most desirable.

This application of the modes of representation primarily dealt with the attitudes of individual MPs and voters. We shall also need to look more closely at the practice of political representation. An 
interesting test for representation from below or from above will be whether the issue positions of parties or MPs change over time to conform more closely to those of their (party's or constituency's) voters, or whether voter positions follow party or MP positions (Esaiasson and Holmberg 1996, 104-08). A possible test for representation ex ante or ex post will be whether politicians or parties campaign primarily on the basis of their records or their proposals, and whether most voters vote retrospectively or prospectively (Fiorina 1981).

Once such attitudinal and behavioral data are available for different countries, the typology can be used in comparative research both as a dependent variable (to uncover the individual and institutional variables that lead to the dominance of a particular mode of representation) and as an independent variable (to study the effects of different modes on policy congruence, political legitimacy, and so on).

The development of this new typology is merely a first step in what we hope to be a renewed interest in political representation as a dynamic relationship between citizens and their elected representatives.

Rudy B. Andeweg is Professor of Political Science at Leiden University, P.O. Box 9555, 2300 RB Leiden, The Netherlands. Jacques J.A. Thomassen is Professor of Political Science at the University of Twente, P.O. Box 217, 7500 AE Enschede, The Netherlands.

\section{NOTES}

This study was made possible by financial support from the Dutch Science Foundation NWO (Grant 410-42-013). The Dutch Institute for Public Opinion and Market Research (TNS NIPO) kindly included questions in its Telepanel survey. This paper was written when both authors were Fellows of the Netherlands Institute of Advanced Study (NIAS) in Wassenaar, The Netherlands. We wish to thank Martin Brothén, Peter Esaiasson, Knut Heidar, Søren Holmberg, Petr Kopecky, Peter Mair, Wolfgang C. Müller, and the journal's anonymous referees for their comments and suggestions.

1. The Dutch Parliamentary Studies of 1968, 1972, 1979, 1990, and 2001 all sought to interview each of the 150 members of the lower house of the Dutch Parliament. In each study, a few MPs could not or would not be interviewed; the average response rate of the studies is $88 \%$. All studies contained both closed and open questions. In the 2001 study, all interviews were recorded on tape so that we can also use the full answers or comments of the MPs to closed questions.

2. By using tests for statistical significance not only for voters but also for MPs, we act as if we interviewed a random sample of MPs, whereas we actually tried (and nearly succeeded) to interview the whole population. 


\section{REFERENCES}

American Political Science Association. 1950. Toward a More Responsible Two-Party System. Washington, DC: American Political Science Association.

Bendor, Jonathan, Ami Glazer, and Thomas H. Hammond. 2001. "Theories of Delegation." Annual Review of Political Science 4: 235-69.

Brennan, Geoffrey, and Alan Hamlin. 1999. "On Political Representation." British Journal of Political Science 29: 109-27.

Converse, Philip E., and Roy Pierce. 1986. Political Representation in France. Cambridge, MA: Belknap.

Esaiasson, Peter, and Søren Holmberg. 1996. Representation from Above: Members of Parliament and Representative Democracy in Sweden. Aldershot: Dartmouth.

Eulau, Heinz, and John C. Wahlke. 1959. "The Role of the Representative: Some Empirical Observations on the Theory of Edmund Burke." American Political Science Review 53: 742-56.

Fearon, James D. 1999. "Electoral Accountability and the Control of Politicians: Selecting Good Types versus Sanctioning Poor Performance." In Democracy, Accountability, and Representation, ed. Adam Przeworski, Susan C. Stokes, and Bernard Manin. Cambridge: Cambridge University Press.

Fiorina, Morris F. 1981. Retrospective Voting in American National Elections. New Haven, CT: Yale University Press.

Inglehart, Ronald. 1977. The Silent Revolution: Changing Values and Political Styles among Western Publics. Princeton, NJ: Princeton University Press.

Judge, David. 1999. Representation: Theory and Practice in Britain. London: Routledge.

Katz, Richard S. 1997. "Representational Roles.” European Journal of Political Research 32: 211-26.

King, Anthony. 1997. Running Scared: Why America's Politicians Campaign Too Much and Govern Too Little. New York: Free Press.

Manin, Bernard. 1997. The Principles of Representative Government. Cambridge: Cambridge University Press.

Manin, Bernard, Adam Przeworski, and Susan C. Stokes. 1999. "Elections and Representation.” In Democracy, Accountability, and Representation, ed. Adam Przeworski, Susan C. Stokes, and Bernard Manin. Cambridge: Cambridge University Press.

Mansbridge, Jane. 2003. "Rethinking Representation." American Political Science Review 97: 515-28.

Méndez-Lago, Monica, and Antonia Martínez. 2002. "Political Representation in Spain: An Empirical Analysis of the Perception of Citizens and MPs." Journal of Legislative Studies 8: 63-90.

Patzelt, Werner. 1997. "German MPs and their Roles." Journal of Legislative Studies 3: 55-78.

Pharr, Susan J., and Robert D. Putnam, eds. 2000. Disaffected Democracies: What Is Troubling the Trilateral Countries? Princeton, NJ: Princeton University Press.

Pitkin, Hanna. 1967. The Concept of Political Representation. Berkeley: University of California Press.

Ranney, Austin. 1954. The Doctrine of Responsible Party Government: Its Origins and Present State. Urbana, IL.: University of Illinois Press. 
Saalfeld, Thomas, and Wolfgang C. Müller. 1997. "Roles in Legislative Studies: A Theoretical Introduction." Journal of Legislative Studies 3: 1-16.

Stimson, James A., M. B. MacKuen, and Robert S. Erikson. 1995. "Dynamic Representation." American Political Science Review 89: 543-65.

Strøm, Kaare. 2000. "Delegation and Accountability in Parliamentary Democracies." European Journal of Political Research 37: 261-89.

Strøm, Kaare. 2003. "Parliamentary Democracy and Delegation." In Delegation and Accountability in Parliamentary Democracies, eds. Kaare Strøm, Wolfgang C. Müller, and T. Bergman. Oxford: Oxford University Press.

Thomassen, Jacques J.A. 1994. "Empirical Research into Political Representation: Failing Democracy or Failing Models." In Elections at Home and Abroad: Essays in Honor of Warren Miller, ed. M. Kent Jennings and Thomas E. Mann. Ann Arbor: University of Michigan Press.

Wahlke, John C., Heinz Eulau, William Buchanan, and LeRoy C. Ferguson. 1962. The Legislative System: Explorations in Legislative Behavior. New York: Wiley. 